\title{
ARTIGOS
}

\section{DA ESTRATÉGIA INDIVIDUAL À AÇÃO COLETIVA: GRUPOS DE SUPORTE E GÊNERO} NO CONTEXTO DA GESTÃO DA DIVERSIDADE

FROM INDIVIDUAL STRATEGY TO COLLECTIVE ACTION: SUPPORT GROUPS AND GENDER WITHIN THE CONTEXT OF MANAGING DIVERSITY

\section{Janette Brunstein}

Professora do Programa de Pós-graduação em Administração da Universidade Presbiteriana Mackenzie - SP, Brasil

janette@mackenzie.com.br

\section{Pedro Jaime}

Doutorando em Antropologia Social pela Faculdade de Filosofia, Letras e Ciências Humanas, Universidade de São Paulo e Professor do Centro de Ciências Sociais e Aplicadas, Universidade Presbiteriana Mackenzie - SP, Brasil

pedrojaime@uol.com.br

Recebido em 03.09.2008. Aprovado em 21.07.2009. Disponibilizado em 09.11.2009

Avaliado pelo sistema double blind review

Editor Científico: Hélio Arthur Irigaray

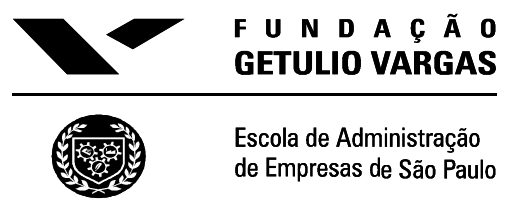




\section{RESUMO}

Este artigo trata da formação de grupo de suporte no marco das políticas de diversidade empresarial. São escassas as pesquisas que abordem essa prática de gestão da diversidade. Visando a contribuir para o preenchimento dessa lacuna, o trabalho analisa um Comitê de Mulheres, a fim de compreender de que forma ele é influenciado pela política de diversidade formatada pela direção da organização e a influencia. Foi realizado um estudo de caso etnográfico em uma corporação transnacional cuja sede no Brasil está localizada em São Paulo. Os resultados apontam para um paradoxo. Por um lado, o Comitê analisado representa um processo de emancipação, sinalizando para práticas gerenciais mais inclusivas e participativas. Por outro, notou-se a presença de mecanismos de controle, uma vez que há um esforço da direção da empresa em disciplinar o seu funcionamento.

PALAVRAS-CHAVE Gestão da diversidade, grupos de suporte, ação coletiva, gênero, etnografia.

ABSTRACT This article deals with the formation of support groups within the context of corporate diversity policies. There is very little research that looks at the practice of managing diversity. In an attempt to contribute to filling this gap this work analyses a Women's Committee in order to understand in what way it is influenced by the diversity policy established by the organization's management and the influence it has. An ethnographic case study was carried out in a transnational company, the Brazilian headquarters of which are located in São Paulo. The results indicate there is a paradox. On the one hand the Committee that was analyzed represents a process of emancipation that point to more inclusive and participative management practices, but on the other it was noted that there are control mechanisms in place, because the management tries to regulate the way it functions.

KEYWORDS Diversity management, support groups, collective action, gender, ethnography. 


\section{INTRODUÇÃO}

A questão da formação e da atuação de grupos de suporte visando minimizar os obstáculos que se colocam à construção da trajetória da mulher nas organizações, as tensões na disputa por poder com que se deparam esses grupos e suas relações com a política de diversidade das empresas constituem a temática central deste artigo. No marco das políticas de diversidade empresarial, os grupos de suporte constituem ações coletivas por meio das quais grupos minoritários e/ou historicamente discriminados e excluídos das posições de maior poder, prestígio e remuneração nas organizações buscam dar apoio emocional e promover a carreira dos seus membros.

Cox Jr e Blake (1991) e Bateman e Snell (1998) mostram que essa prática vem sendo adotada nos EUA em empresas de diferentes áreas de negócios. No caso brasileiro, a literatura de difusão sobre o universo empresarial revela a mesma tendência (GIANNASI, 2006; O Estado de São Paulo, 2003). A despeito dessa evidência empírica, embora já existam no Brasil trabalhos que abordem a gestão da diversidade (FLEURY, 2000; ALVES e GALEÃO-SILVA, 2004; HANASHIRO, 2007), não há pesquisas que tratem da prática específica dos grupos de suporte. A fim de contribuir para o preenchimento dessa lacuna, foi realizado um estudo em um Comitê de Mulheres criado no âmbito das políticas de diversidade de uma corporação transnacional, cuja sede no Brasil está situada na cidade de São Paulo e que está presente em quase todo o território nacional. Buscou-se na pesquisa dialogar com algumas questões agrupadas em dois eixos.

O primeiro refere-se à estruturação e atuação do Comitê de Mulheres. Nesse sentido, foram colocadas as seguintes perguntas: qual o histórico desse Comitê? Como ele se formou? Quem são as mulheres que dele fazem parte? Como se organizam? Como constroem a identidade/ideário desse coletivo? O segundo trata das tensões entre a ação coletiva desenvolvida pelo Comitê e as políticas de diversidade formatadas pela direção da empresa. Foram formuladas então as seguintes questões: de que forma a estruturação do Comitê é influenciada pelas políticas de diversidade da empresa e as influencia? Qual a autonomia que a direção da organização confere ao seu funcionamento? De que maneira responde às suas demandas, reivindicações ou propostas? A ação desenvolvida pelo Comitê possui reflexos na alteração das relações de gênero no universo da empresa? Os princípios fundadores da desigualdade estão sendo revistos? Os padrões de pensar e agir estão sendo modificados?

A partir dessas questões, pretendeu-se contribuir com o avanço dos estudos de gestão da diversidade no Brasil, problematizando um possível paradoxo. Por um lado, a formação nas empresas de núcleos de suporte talvez se configure como um processo de emancipação, sinalizando para práticas 
ARTIGOS - DA ESTRATÉGIA INDIVIDUAL À AÇÃO COLETIVA: GRUPOS DE SUPORTE E GÊNERO NO CONTEXTO DA GESTÃO DA DIVERSIDADE

Janette Brunstein - Pedro Jaime

gerenciais mais inclusivas, igualitárias e participativas. E, por outro lado, essa prática pode representar um mecanismo de controle que visa disciplinar o funcionamento desses grupos.

\section{ABORDAGEM METODOLÓGICA E ESTRATÉGIAS DE INVESTIGAÇÃO}

A abordagem metodológica que orientou a pesquisa foi o estudo de caso do tipo etnográfico (HAMEL e outros, 1993; ANDRÉ, 1995). De maneira geral, o estudo de caso refere-se ao estudo em profundidade de uma ou mais unidades particulares, a partir da sua observação, reconstituição e análise (BECKER, 1999; GODOY, 1995, 2006). Nesta pesquisa, apenas uma unidade foi tomada como objeto do estudo: o Comitê de Mulheres criado no âmbito das políticas de diversidade de uma corporação transnacional. Todavia, existem diferentes formas de pensar a concretização do estudo de caso. Não partimos da perspectiva positivista representada por Yin (2001), mas da socioantropológica proposta por Hamel e outros (1993). Dessa perspectiva, recorre-se, sobretudo, à observação e a entrevistas para a construção dos dados. Tal abordagem qualitativa na condução do estudo de caso possui suas origens nos trabalhos sociológicos desenvolvidos pelos representantes da chamada Escola de Chicago, bem como na monografia etnográfica realizada pelo antropólogo Bronislaw Malinowski (HAMEL e outros, 1993). É a partir dessa segunda linha que orientamos esta pesquisa.

O trabalho de campo realizado por Bronislaw Malinowski nas Ilhas Trobriand, nordeste da Nova Guiné, no primeiro quarto do século XX, está associado ao nascimento da moderna etnografia. Até então, os antropólogos produziam suas reflexões teóricas a partir das observações de outras sociedades/culturas empreendidas por viajantes, missionários e funcionários do governo colonial. Malinowski rompe com a chamada antropologia de gabinete, propondo a fusão, em um mesmo indivíduo, entre o teórico e o observador (L’ESTOILE, 1999). Argumentava que somente um olhar disciplinado, isto é, um olhar que apreende a realidade dentro do esquema conceitual fornecido pela teoria antropológica (CARDOSO de OLIVEIRA,2000) poderia recolher os dados etnográficos necessários à compreensão do outro. Ademais, acentuava a necessidade de o pesquisador tomar parte da vida cotidiana da sociedade estudada, deixando de ser um elemento estranho, perturbador, fundando assim a observação participante. Esse procedimento seria indispensável a uma familiarização maior com o padrão cultural dessa sociedade, tornando possível captar o ponto de vista dos próprios sujeitos sobre sua sociedade e cultura. 
A partir de então, a etnografia constituiu-se no método de pesquisa por excelência da antropologia, a sua marca distintiva no campo das ciências sociais. O trabalho de campo etnográfico tem sido representado como o "laboratório" científico da disciplina antropológica (CLIFFORD, 1998), o local onde são levadas a cabo o que Laplantine (2000) definiu como "experimentações in vivo", por oposição as "experimentações in vitro".

Ainda que seja considerada o método de pesquisa por excelência da antropologia, não existe consenso entre os antropólogos sobre o significado da prática etnográfica (JAIME, 2003). No caso deste estudo, a orientação básica foi fornecida pela abordagem interpretativa de Clifford Geertz (1989; 1998). Para o antropólogo estado-unidense, a etnografia consiste em uma prática de pesquisa microscópica, sistemática e de longa duração. O objetivo do pesquisador é empreender uma descrição densa do universo pesquisado, isto é, uma descrição capaz de capturar e interpretar os sentidos que os sujeitos, objeto do estudo, atribuem às suas ações. Ele ressalta ainda que a etnografia deve problematizar os esquemas conceituais produzidos no universo acadêmico. Para tanto, faz-se necessário confrontar os saberes locais, isto é, conceitos que os sujeitos sociais utilizam para definir como pensam e sentem o mundo, com o saber antropológico, ou seja, conceitos que os etnógrafos utilizam para construir sua análise. Dessa forma, ao articular de maneira dialética a experiência de campo com a literatura científica, a etnografia seria a fonte de renovação teórica da antropologia. Tratase, portanto, de pensar as perspectivas indutiva e dedutiva não como excludentes, mas como complementares.

Essa abordagem mostrou-se adequada, uma vez que nesse estudo pretendeu-se descrever e interpretar uma experiência de formação de grupos de suporte no âmbito do programa de diversidade de uma empresa, a partir do confronto entre a revisão de literatura sobre a temática e a percepção dos próprios atores sobre a experiência em análise. Ou seja, não se tratou de privilegiar uma perspectiva teórica em particular, mas avaliar em que medida as diferentes abordagens conceituais se aproximam e em que medida se distanciam do caso estudado, tal como visto pelos próprios sujeitos.

Para a concretização do método etnográfico, acompanharam-se durante um ano reuniões mensais ordinárias e alguns encontros extraordinários e/ou eventos realizados pelo Comitê de Mulheres. Vale ressaltar que, no caso da pesquisa em organizações, a observação de reuniões e eventos é apontada por Schwartzman (1992) como uma importante via para levar a cabo a etnografia. Seguindo sugestões fornecidas por Aktouf (1987) e Serva e Jaime (1995) para a aplicação deste método no campo dos estudos organizacionais, as observações etnográficas foram orientadas por rubricas definidas com base nas perguntas de pesquisa. Foram elas: histórico do comitê de mulheres; sua 
estruturação e estratégias de ação; perfil das componentes; identidade e ideário do coletivo; sua inserção no contexto das políticas de diversidade da empresa; sua autonomia/regulação; obstáculos à sua atuação; impacto das suas ações na alteração das relações de gênero na empresa. As observações orientadas por essas rubricas foram registradas separadamente pelos pesquisadores por meio de anotações nos diários de campo. Tais anotações constituíam narrativas, por meio das quais os pesquisadores descreviam as reuniões do Comitê e contavam o que se passava no campo, sem esquecer das suas próprias impressões. Isto porque, conforme apontado nos debates contemporâneos em torno da etnografia, observação e interpretação não são momentos estanques, mas inter-relacionados. Quanto a esse ponto, Laplantine (2000) ressalta que descrever é, simultaneamente, compreender e interpretar. Olivier de Sardan (2008), por sua vez, adverte que o etnógrafo descreve sempre a partir de um ponto de vista. Assim, recomenda-se que o diário já deve conter as interpretações formuladas pelo pesquisador. Nele estão evidenciados os avanços e recuos na compreensão do grupo estudado desde a entrada no campo até o momento em que essa etapa é considerada encerrada.

Para esclarecer e/ou complementar as informações levantadas por meio da observação, foram realizadas entrevistas, procedimento de extrema importância no uso da abordagem etnográfica. Isto basicamente por duas razões. De um lado, porque a observação participante não permite aceder a determinadas informações necessárias à pesquisa, sendo necessário recorrer às lembranças e ao saber dos próprios sujeitos, objeto do estudo. De outro lado, em razão da sua importância para a compreensão do ponto de vista dos atores sobre sua própria realidade, que, conforme apontado acima, configura-se como algo central na perspectiva etnográfica (OLIVIER de SARDAN, 2008). Vale ressaltar que nessa perspectiva a entrevista é pensada como uma interação dialógica, uma conversação. Trata-se da modalidade de entrevista que Olivier de Sardan (2008) denominou de socioantropológica e Kaufmann (2007) de compreensiva. Nesse caso, o papel do pesquisador é facilitar a produção de um discurso, de uma narrativa por parte do entrevistado. Narrativa é pensada aqui no sentido minimalista proposto por Bertaux (2006), para quem um discurso assume a forma narrativa quando um sujeito conta (e o verbo contar, fazer um relado de, é fundamental em sua concepção) a outra pessoa, pesquisador ou não, episódios da sua experiência vivida.

Quatro componentes do coletivo foram entrevistadas: uma das fundadoras, a líder atual, uma integrante com destacada participação nas reuniões e uma gestora do Departamento de RH, voltada para a política de diversidade, que tem acento no Comitê de Diversidade da empresa. Foi realizada uma entrevista de cerca de duas horas de duração com cada uma delas, a partir de um roteiro que se baseou nas mesmas rubricas que orientaram a observação. 
Além disso, próximo ao final do trabalho de campo, empreendeu-se uma reunião devolutiva com as componentes do Comitê, ocasião em que foi avaliada a pertinência das interpretações construídas durante o trabalho de campo. Quanto a esse procedimento, cabe destacar uma advertência feita pelo antropólogo Ulf Hannerz (1997), para quem as interpretações dos etnógrafos não são necessariamente validadas ou invalidadas pelo fato de coincidirem ou não com as interpretações ordinárias construídas pelos sujeitos, objeto da pesquisa. A rejeição da interpretação etnográfica pelos sujeitos não significa que ela seja desprovida de valor científico. Tomando essa ressalva para pensar o campo dos estudos organizacionais, Jaime (2003) afirma que a leitura que os atores fazem da interpretação construída sobre eles não deve ser tomada como o juízo final sobre a veracidade da análise organizacional e sim como mais um dado que fala sobre o processo dialógico que constitui a pesquisa etnográfica em organizações. Essa reunião devolutiva não foi pensada, portanto, em um registro positivista, como o momento de verificar/validar a coleta de dados. Mas sim, em um registro interpretativo/hermenêutico, como um espaço em que os pesquisadores e seus interlocutores puderam vivenciar uma confrontação dialógica, negociar seus pontos de vista sobre a realidade (GEERTZ, 1989; LAPLANTINE, 2000).

No que se refere ao final do trabalho de campo, vale ressaltar que, na abordagem etnográfica, não há um tempo predeterminado para sua duração. Todavia, existe uma regra básica a ser seguida: só se deve deixar o campo quando se percebe que o processo de observação chegou a um ponto de saturação. Ou seja, quando os eventos observados não trazem mais novas informações, novos sentidos com relação ao problema de pesquisa (OLIVIER de SARDAN, 2008).

Os dados construídos na investigação passaram por uma interpretação de segunda ordem por meio da análise de narrativas. Aqui é importante empreender alguns esclarecimentos. Primeiramente, cabe destacar a ideia de que os dados foram construídos. Espera-se que tenha ficado claro que, nessa abordagem, os dados não são dados, não são recolhidos pelo etnógrafo à maneira do zoólogo ou do botânico. Eles são fabricados por meio do encontro comunicativo com os sujeitos, objeto da pesquisa, com quem se partilha, de maneira suficientemente duradoura, uma experiência (RABINOW, 1992; LAPLANTINE, 2000). Em seguida, vale observar que a chamada análise dos dados constitui uma interpretação de segunda ordem, na medida em que, conforme apontado anteriormente, a interpretação em primeira ordem se dá ao longo do encontro etnográfico, devendo ser registrada no diário de campo (CARDOSO de OLIVEIRA, 2000).

Finalmente, é preciso delimitar os marcos dentro dos quais se fala em análise de narrativas nessa pesquisa. Quanto a esse ponto, a primeira consideração necessária a fazer é que tal análise não foi 
pensada aqui dentro dos parâmetros fornecidos pela linguística. Não se buscou construir as interpretações a partir de seleções lexicais ou outros procedimentos da chamada análise do discurso própria das ciências da linguagem. Coerente com a abordagem metodológica para a construção dos dados estabelecida nesta pesquisa, a análise de narrativas foi trabalhada dentro de uma perspectiva socioantropológica. No campo dos estudos organizacionais, essa perspectiva já foi experimentada, dentre outros, por Czarniawska (1998; 2002). Parte-se de uma visão das organizações não como uma realidade objetiva: entidades concretas, racionais e estáveis. Mas como atividades expressivas que simultaneamente as criam, transformam ou falam sobre elas. São tomados como narrativas então, de um lado, os relatos que os próprios atores constroem para interpretar suas experiências na organização e que são recuperados na interação comunicativa com o pesquisador. São as tales from the field, reconstruídas nas entrevistas dialógicas. De outro lado, as interpretações que os pesquisadores constroem sobre a dinâmica da organização pesquisada, as tales of the field, anotadas no diário de campo. Ambas as narrativas são analisadas visando compreender o que elas dizem sobre a experiência social em análise, no caso desta pesquisa: a formação do Comitê de Mulheres; seu ideário e identidade; sua dinâmica e autonomia em relação à política de diversidade da empresa; e, finalmente, suas ações e estratégias.

\section{DISCUSSÕES TEÓRICAS}

Nkomo e Cox (1998) apontam a contribuição da teoria das relações intergrupais incrustadas nos estudos de gestão da diversidade. Essa corrente teórica preconiza, de um lado, que na organização convivem grupos de identidade cujos membros compartilham características biológicas e/ou sociais comuns. Os sujeitos se autoidentificam, podendo ou não se aproximar de seu grupo de identidade. De outro lado, estão os grupos organizacionais, cujos integrantes compartilham cargos e experiências de trabalho equivalentes. O Comitê de Mulheres objeto desta pesquisa pode representar um grupo de identidade que busca fazer parte de grupos organizacionais de poder. É na interface desses grupos, na zona de interseção, que conflitos se estabelecem. Conflitos estes que se dão no interior do suprasistema organizacional em que os grupos estão incrustados. A leitura dessa teoria sugere capturar a dinâmica entre os grupos de identidade, os grupos organizacionais e o supra-sistema em que estão enraizados. 
Dado que na presente pesquisa a filiação a um grupo de identidade se dá por um processo formal e instituído pelo supra-sistema organizacional, é importante saber como essas mulheres estão construindo sua identidade coletiva. Talvez a luta pelo direito de ser "si mesmas" (BELLE, 1993) e ascender na empresa se estabeleça agora por um processo de identificação grupal legitimado. Cabe então lançar as seguintes perguntas: quais os reflexos desse arranjo organizacional para a construção da identidade de gênero e para a disputa pelo poder? Qual a consequência para a identidade desse coletivo do fato de o mesmo existir no contexto de uma organização que afirma valorizar a diversidade e institucionaliza um grupo de identidade?

A definição de grupo é um ponto de partida para pensar sobre essas questões. Alderfer e Smith (1982) definem grupo como um conjunto de indivíduos que apresentam algumas características específicas, a saber: 1) estabelecem relações interdependentes significativas uns com os outros; 2) percebem a si mesmos como representantes de um coletivo, distinguindo-se daqueles que não são membros; 3) são reconhecidos pelos não-membros como pertencentes a uma coletividade; 4) atuando sozinhos ou em conjunto, mantêm relações de interdependência significativa com outros grupos; e 5) distribuem papéis em seu interior em função das expectativas do próprio grupo, bem como de membros de outros grupos.

A existência de uma correlação entre mobilização de grupos para a ação coletiva, percepção de injustiça e possibilidade de mudança é apontada por Deaux e outros (2006). Eles afirmam que o engajamento das pessoas em uma ação coletiva expressa a forma de estabelecer a posição de seu grupo em um contexto marcado por desigualdades. Tal engajamento dependerá do grau de identificação do grupo, seu status e poder, bem como do endosso da ideologia dos seus membros. Argumentam também que o suporte do grupo é outro fator que mobiliza as pessoas a se integrarem.

Mas o que se entende por ação coletiva? De acordo com Tajfel e Turner (1979) trata-se de uma estratégia de afirmação de um grupo social desfavorecido em comparação com outros, visando promover mudanças. Já Wright e Troop (2002) apontam que ação coletiva deve ser compreendida como aquela que, partindo de um núcleo representativo, está comprometida com a promoção de melhorias para todo o grupo social que esse núcleo representa.

E qual a eficácia das ações coletivas? Para Simpson e Macy (2004) a formação de coalizões entre atores estruturalmente em desvantagem é fundamental para balancear as iniquidades de poder. Eles apontam, entretanto, que o estabelecimento dessas coalizões depende decisivamente da habilidade de superar a tendência à inércia. Partindo desse raciocínio, argumentam que dois fatores preponderantes influenciam as mudanças na balança do poder. De um lado, a motivação para a 
formação da coalizão entre atores estruturalmente em desvantagem. De outro, o êxito alcançado nessa articulação. Ressaltam ainda a importância de os participantes do grupo minimizarem os desequilíbrios de poder internos ao próprio grupo.

Hargrave e Van de Ven (2006), por sua vez, discutem a importância da ação coletiva para os processos de mudança. Sugerem que se observe, por meio de narrativas construídas pelos sujeitos que vivenciaram o processo, quais foram os mecanismos que levaram à transformação e as circunstâncias ou contingências que estavam por trás. Analisando pesquisas cuja preocupação central é entender inovação institucional por meio da ação coletiva, chegam à conclusão de que esta emerge de um processo dialético no qual atores em oposição no campo organizacional compõem temas e formam redes na intenção de introduzir um novo arranjo institucional, em um contínuo processo de tese, antítese e síntese.

No caso deste artigo, para saber se uma ação coletiva empreendida por meio de um grupo de suporte contribui para alterar as relações de gênero e estabelecer novos padrões de pensar e agir na organização é preciso antes entender o que é um grupo de suporte. Estes podem ser definidos como coletivos organizados por pessoas que fornecem, umas às outras, vários tipos de ajuda para características opressivas particulares vividas por elas. A ajuda pode ser no sentido de relatar experiências pessoais, ouvir as experiências dos outros, promover entendimento mútuo, estabelecer uma rede de relações sociais e prover informações relevantes (VANDENBOS, 2007). A participação em grupos dessa natureza possibilita aos seus membros um apoio emocional para enfrentar situações críticas. Ademais, o aprendizado gerado com as experiências partilhadas alimenta a esperança de mudanças (YALOM, 1995).

Analisando a literatura sobre essa temática, Kahnweiler e Riordan (1998) constataram que muitos autores consideram o próprio local de trabalho como um grupo de suporte. Dessa perspectiva, por meio de ligações espontâneas entre empregados, estabelecem-se informalmente relações de ajuda mútua. Mas, em alguns casos, esses vínculos podem gerar iniciativas mais organizadas e estruturadas no âmbito da empresa. Nessa linha de raciocínio, Riordan e Kahnweiler (1996) apontam que um modelo que o grupo de suporte pode assumir é aquele em que o propósito é promover a educação e desenvolver competências de seus membros, de forma que sejam capazes de estabelecer networks e progredir. A intenção é aprender como alcançar as metas de carreira. Dentre os resultados desse tipo de grupo, estão: aumento de habilidades estratégicas, ampliação da rede de contatos e desenvolvimento da capacidade de liderança. 
Kahnweiler e Riordan (1998) também chamam a atenção para a existência de grupos de suporte que funcionam no interior das organizações e apresentam características peculiares. Trata-se daqueles coletivos formados por indivíduos que pertencem a grupos de identidade específicos, reconhecendo e enfatizando determinadas localizações sociais, tais como gênero, raça-etnia, sexualidade etc. Tais grupos têm por objetivo promover um fórum para discussão dos desafios de trabalhar em um ambiente diverso marcado por barreiras e dificuldades. O formato assinalado pelos autores é bastante próximo daquele encontrado no Comitê objeto desta pesquisa.

No que se refere especificamente aos grupos de suporte dedicados à questão da trajetória profissional da mulher nas empresas, vale lembrar um raciocínio construído por Osório (2002). Analisando a problemática da ação das mulheres no interior dos centros de poder, a pesquisadora aponta que "a capacidade de transformar as organizações políticas por dentro do modelo dominante tem constituído, a partir de meados da década de 1980, um dos focos da atenção do movimento feminista" (p. 422). Em analogia a esse raciocínio, pode-se dizer que reside aí a importância de se estudar o processo de formação desses comitês de mulheres nas empresas: onde nascem, como se estruturam e atuam, se consolidam, se normatizam e desenvolvem estratégias.

Dado que o Comitê em estudo nesta pesquisa se articula em torno da identidade de gênero, fazse necessário situar alguns debates nesse campo de estudos. Segundo Joan Scott (1988), uma das principais teóricas do tema, gênero diz respeito às formas como cada sociedade elabora significados a respeito das diferenças sexuais e estrutura as relações entre homens e mulheres. Portanto, essas diferenças não estão dadas em uma essência, sendo construídas e reconstruídas. Quando da constituição do campo dos estudos de gênero nos anos 1970, diversos autores denunciaram a universalidade da dominação masculina. Argumentaram que todas as sociedades, qualquer que fosse seu modelo de organização familiar ou base econômica, eram estruturadas a partir da supremacia masculina. Explicaram a suposta existência desse fenômeno por meio da oposição entre espaço privado e esfera pública. Dessa perspectiva, os sistemas socioculturais identificariam o lugar da mulher como prioritariamente associado, quando não exclusivamente vinculado, ao espaço doméstico, devido ao seu papel de mãe. Já o homem estaria mais livre para se dedicar à vida pública (ROSALDO e LAMPHERE, 1979).

Essa perspectiva é questionada pelos debates contemporâneos. Busca-se superar a maneira estática com que alguns analistas enxergaram as relações de gênero. Bourdieu (2005), por exemplo, insistiu na ideia de dominação masculina. Por um lado, na construção do seu argumento, ele critica o pressuposto da determinação biológica, ao advogar que ocorre na verdade a busca por legitimar uma 
relação de dominação, inscrevendo na natureza o que é, na verdade, uma construção social naturalizada. Seu esforço visa desvelar os mecanismos históricos de reprodução das desigualdades, dos quais fazem parte agentes específicos, como a família, a escola, a Igreja e o Estado.

Por outro lado, em sua abordagem, tudo se passa como se houvesse apenas esforços de manutenção e não, também, de transformação dos mecanismos de dominação. Presas/os aos habitus de gênero que nelas/es são inculcados através dos processos de socialização, as mulheres, e também os homens, seriam incapazes de redefinir os discursos e as relações de gênero hegemônicas. O sociólogo escreve, portanto, de costas para os avanços conquistados pelo movimento feminista, sobretudo desde os anos 1970, bem como para a produção teórica das intelectuais feministas (CORREA, 1999; FOURNIER, 2002).

Uma alternativa a essa abordagem é fornecida por Moore (1994; 2000), para quem a identidade de gênero não é algo passivo, adquirido de uma vez por todas pela socialização. Ela defende a ideia de que há uma relação mais complexa entre discursos de gênero e identidade de gênero, ou seja, entre gênero construído em operações de significação e gênero vivido, negociado e renegociado constantemente pelos sujeitos sociais. Ressalta também que uma mesma sociedade possui uma multiplicidade de discursos de gênero, contraditórios e conflitantes, que operam em diferentes contextos sociais. Embora hierarquicamente ordenados, esses discursos são afeitos à mudança. Consequentemente, é fundamental compreender a natureza hierárquica das relações de gênero produzidas em cada situação, mas também os esforços de transformação no padrão dessas relações.

Alinhados com essa perspectiva e enfocando o universo empresarial, Charmes e Wieringa (2003) afirmam que a transformação das desigualdades de gênero nas empresas depende da capacidade de mobilização interna das mulheres. Apontam a importância de elas apresentarem habilidade de organização, atrelada ao nível de conhecimento e à consciência das forças que operam no cenário em que se encontram.

Outra questão fundamental nos debates contemporâneos nesse campo diz respeito à desconstrução da ideia de gênero como algo relativo a uma identidade unificada, definida pela categoria mulher. Argumenta-se que se alguém "é" uma mulher, isso certamente não é tudo que esse alguém é. Isto porque a identidade gênero estabelece interseções com outras localizações sociais: classe, raça-etnia, sexualidade, etc. Portanto, falar em mulheres, no plural, seria mais adequado do que pensar essa identidade a partir de uma pretensa homogeneidade. O descentramento da categoria gênero não implica negar a possibilidade de uma coalizão entre as mulheres. Contudo, obriga a uma vigilância analítica, a fim de evitar a antecipação dessa solidariedade, tomada como dada a priori (BUTLER, 
2003). No âmbito dos estudos organizacionais, Ely e Mayerson (1999) atentam para esses cuidados, ao afirmarem que as organizações não são simplesmente tipificadas por gênero, sendo também atravessadas por etnia e classe social.

A complexidade da discussão em torno da identidade de gênero é igualmente encontrada no debate que se trava neste trabalho sobre as possibilidades de emancipação e autonomia das mulheres que empreendem uma ação coletiva no contexto regulado das organizações empresariais. Cabe então uma breve elucidação do que se está entendendo por autonomia e por emancipação.

Antes de tratar desses conceitos-chave, é preciso esclarecer que os teóricos privilegiados pelos autores deste trabalho para apoiar suas análises sobre emancipação e autonomia não se referem diretamente ao universo empresarial. Todavia, acredita-se que suas definições podem ser consideradas válidas para analisar a ação coletiva e o movimento das mulheres nesse espaço.

Como bem expressa Santos (2000a; 2000b), a tensão entre regulação social e emancipação social se estabelece na modernidade como um embate no qual as energias emancipatórias vão sendo transformadas em energias regulatórias. Há um desequilíbrio entre emancipação e regulação, que se dá pelo excesso de regulação. Tal excesso conduz, por vezes, a situações nas quais se tem a falsa impressão de que há emancipação. Cabe assim observar como o Comitê em estudo transita entre regulação e emancipação e de que forma um possível caráter excessivo no mecanismo regulatório pode conduzir a um simulacro de emancipação nessa experiência.

Giddens (2002, p. 194), ao tratar de política emancipatória, a define como "uma visão genérica, interessada, acima de tudo, em libertar os indivíduos e grupos das limitações que afetam negativamente suas oportunidades na vida". Isso implica um esforço em empreender uma atitude transformadora que permita um rompimento com uma situação do passado e que leve a um avanço em direção a uma nova realidade. Para ele, o objetivo de toda política emancipatória é o de superar a dominação ilegítima de alguns indivíduos ou grupos sobre outros, o que se faz pelo aumento do controle que os sujeitos tem sobre as circunstâncias da sua vida. Aponta, assim, que a política emancipatória torna imperativo os valores de justiça, igualdade e participação.

A natureza da emancipação, para Giddens (2002, p. 195), está na capacidade de indivíduos ou grupos desenvolverem suas potencialidades dentro dos quadros das limitações sociais. Ou seja, para ele "a política emancipatória opera com uma noção hierárquica do poder", entendido em sua acepção weberiana, isto é, "como a capacidade de um indivíduo ou grupo exercer sua vontade sobre os outros". Consequentemente, "a política emancipatória se ocupa de reduzir ou eliminar a exploração, a desigualdade e a opressão". Dessa maneira, resta a presente investigação saber se a formação de grupos 
de suporte no interior das organizações pode ser considerada um caminho viável e interessante para atingir esse propósito emancipatório.

Giddens aponta ainda que a emancipação rompe com a rigidez da tradição e das condições da dominação hierárquica, ainda que não a elimine por completo. O motor que mobiliza essa política emancipatória é a autonomia, entendida por ele como a ação de indivíduos livres e iguais.

O indivíduo é libertado de limitações impostas ao seu comportamento como resultado de condições exploradoras, desiguais ou opressivas; mas ele não é libertado em termos absolutos. [...] As condições básicas que governam a autonomia da ação são formuladas em termos de uma temática de justiça (GIDDENS, 2002, p. 196).

Assim, a autonomia do Comitê de Mulheres no presente estudo se refere ao grau de escolha e de liberdade desse coletivo no escopo de uma ordem justa, mesmo que se considere em aberto o que significa uma ordem justa, como bem coloca Giddens (2002). Mas não é só a capacidade de escolha e liberdade que compõe a autonomia; o controle que têm os indivíduos na organização também é indicador importante (TOURAINE, 1998). Para Touraine (1998, p. 40) o ator social, definido por ele como "indivíduos ou grupos capazes de modificar seu meio e de afirmar ou de reforçar seu controle sobre as condições e as formas de suas atividades", se engaja em relações sociais concretas, profissionais, econômicas, e busca aumentar sua autonomia, controlar o tempo e as condições de seu trabalho. Dessa forma, cabe questionar se a autonomia conferida ao (ou conquistada pelo) Comitê de Mulheres permite que esse coletivo seja capaz de definir estratégias em direção a processos de mudança que não somente valorizem a diferença e promovam a igualdade, mas também que não façam das diferenças fontes de desigualdades.

É no marco dessas discussões teóricas que se empreende, nas próximas seções, a descrição etnográfica e a análise do caso, objeto desse estudo.

\section{"E FOMOS ESCREVENDO ESSA HISTÓRIA": BREVE HISTÓRICO DO COMITÊ DE MULHERES}

O Comitê de Mulheres da empresa surgiu de uma demanda trazida pelo presidente no quadro das políticas de diversidade que estavam sendo implantadas. Foi montada uma equipe com cerca de 20 
profissionais, em sua maioria posicionadas em cargos de direção ou alta gerência, que deram início a essa experiência. Começaram com um survey com o conjunto das mulheres da organização. A partir desse levantamento foi elaborado um plano validado com a diretoria executiva. Dele constaram algumas ações, dentre as quais se destacam a criação de um lactário e a construção de um programa de mentoring para dar suporte ao desenvolvimento da carreira das mulheres.

Paralelamente, as componentes do Comitê decidiram que seria importante ganhar maior consistência no que se refere à história das mulheres e das relações de gênero. Acreditavam na necessidade de um fortalecimento conceitual para enfrentar obstáculos que surgiriam. Contataram uma intelectual do campo das ciências humanas e sociais com vasta trajetória de pesquisa sobre gênero e iniciaram uma formação. Nessa época, o coletivo ainda não estava institucionalizado na política de diversidade da empresa e atuava de maneira informal. Tratava-se de um grupo "pirata", como as atuais componentes costumam denominar, se referindo ao fato de que não tinham orçamento próprio e para concretizar suas atividades precisavam captar, de maneira ad hoc, recursos alocados em departamentos onde existiam pessoas aliadas. Na verdade, o próprio programa de diversidade da empresa estava surgindo nesse período. O certo é que retiravam dinheiro do próprio bolso para fazer essa capacitação.

Com o decorrer do tempo, houve mudanças na formação do Comitê, atribuídas pelas componentes a uma rotatividade natural. As pessoas davam sua contribuição e, à medida que se envolviam em projetos organizacionais que demandavam muita dedicação, se desligavam, abrindo espaço para uma necessária renovação. Todavia, constatou-se um padrão nesse processo de modificação na composição do coletivo. As executivas que ocupavam postos de maior poder na estrutura organizacional saíram e mulheres mais jovens e/ou posicionadas em cargos menos elevados na hierarquia da empresa assumiram seus lugares.

Pode-se interpretar esse padrão como algo característico da dinâmica dos negócios. Novos projetos são iniciados por líderes que assumem a responsabilidade inicial. Em seguida, quando os primeiros desafios são vencidos e aprendizados básicos gerados, essas pessoas se desligam do dia-a-dia do projeto, assumindo novas frentes e passando sua gestão para outros membros da organização. Contudo, os resultados da pesquisa apontam para a necessidade de uma interpretação que leve em conta uma complexidade política maior. O universo empresarial é fortemente marcado pela dominação masculina. As mulheres são minoritárias nos postos de poder e defender seus interesses em termos de gênero ainda é algo controverso. Ademais, o alto escalão das empresas está longe de constituir um espaço de militância e luta por direitos. À medida que se sobe na hierarquia organizacional, determinadas questões não transitam livremente, a não ser em espaços vigiados, disciplinados por 
mecanismos explícitos ou sutis de controle. Assim, acredita-se que essas mulheres, embora escaladas para dar início ao Comitê, perceberam que corriam riscos no desenvolvimento de suas carreiras, caso sofressem o desgaste que representa a atuação na linha de frente nessa temática. Colocaram então outras nos seus lugares e passaram para a retaguarda, continuando a ajudar nos bastidores.

Essa interpretação parte de indícios levantados no trabalho de campo. Diversas componentes do Comitê apontaram para as dificuldades que representa se mover nesse terreno. Isso fica bastante claro na fala de uma delas sobre as táticas de que o coletivo fazia uso na sua origem: "Vamos fazer, me encontra em casa, eu te mando por e-mail. Manda no meu hotmail porque isso daqui é polêmico". Os trechos de algumas entrevistas transcritos abaixo também são esclarecedores nesse sentido:

Eu acho que hoje já não é mais um... As meninas não falam mais escondidas. [...] No começo, a gente fazia reunião antes do horário, porque se alguém descobrisse que a gente tratava desse tema no horário do trabalho...

Elas tinham problemas de vir à reunião..., de participar, sabe? Era uma coisa assim: "Pô, mas se o meu chefe descobrir que eu estou participando, como será..., como vou explicar?" Era uma coisa meio clandestina.

Pode-se sugerir aqui uma contradição entre o fato de a demanda de criação desse Comitê ter partido do presidente e a sensação de clandestinidade expressa nas falas acima. Essa contradição de fato existe. Mas é importante ressaltar que ela existe justamente porque as organizações, como processos dialéticos, são plenas de contradições. O fato de uma política ser sancionada pelo presidente não quer dizer que, automaticamente, todos os diretores e gerentes estejam plenamente convencidos da sua importância. Ao contrário, muitos revelam resistências. Isso aconteceu no caso estudado, fazendo com que as mulheres tivessem que buscar estratégias para contornar essas resistências. Parte dessas estratégias refere-se ao apoio das fundadoras, ainda que a partir dos bastidores. Esse ponto fica explícito na reflexão feita pela atual líder ao tratar de uma das antigas componentes, pessoa que é muito forte na memória dessa experiência.

E ao mesmo tempo a Mariana [nome fictício] saiu desse núcleo duro, saiu do Comitê por conta da exigência do chefe. E ela..., e nós montamos um grupo de executivas que nos apoiam. E a Mariana passou a ser uma delas. Ela não podia ter o nome dela vinculado ao Comitê. Então, pra todo mundo que perguntava, ela falava: "Não, não 
ARTIGOS - DA ESTRATÉGIA INDIVIDUAL À AÇÃO COLETIVA: GRUPOS DE SUPORTE E GÊNERO NO CONTEXTO DA GESTÃO DA DIVERSIDADE

Janette Brunstein - Pedro Jaime

pertenço mais." E por trás sempre nos apoiando, em todos os momentos: "Faço assim, ou faço assado, o que você acha? Ah, vamos assim." Então eu tinha um grupo aqui de executivas, nós temos até hoje. E quem são essas executivas? São supermaster, né? (risos) [...] Eu tenho cinco mulheres, que são altas, grandes, e que nos ajudam dando suporte.

O Comitê estabeleceu então esse padrão de atuação. Hoje, ele possui cerca de 20 componentes, que realizam reuniões mensais. Cinco mulheres, todas localizadas em posições intermediárias na estrutura organizacional, são as mais atuantes. Elas protagonizam o coletivo.

\section{“NÃO TEM COMO QUEIMAR O SUTIÃ, SE QUEIMAR, ESTÁ FORA”: IDENTIDADE E IDEÁRIO DO COMITÊ}

A discussão sobre a identidade e o ideário do Comitê causou estranheza quando apareceu nas entrevistas. Tudo se passa como se ele estivesse atravessando uma crise, vivendo um momento de inflexão que demanda uma reflexão sobre sua razão de ser, seus pressupostos e objetivos. "A identidade? [...] Que pergunta, não é? Você devia ter mandado um e-mail antes, para eu pensar... (risos) Essa é daquelas entrevistas em que a pessoa fica...", ponderou uma delas. "A identidade do Comitê? Não sei. Antes eu saberia, hoje eu não sei. Eu acho que existe uma transição aí acontecendo", apontou outra.

As componentes do Comitê assinalaram um distanciamento com relação ao movimento feminista. Pode-se dizer que se trata de um afastamento deliberado da ideia de feminismo. "Mas assim, dizer que nós somos um movimento feminista, eu acho um pouco pesado... porque o próprio movimento hoje em dia já está mais descaracterizado", destacou uma delas. Não parece ser algo surpreendente essa negação do movimento feminista. Primeiramente, porque estamos falando de mulheres que buscam uma inserção no topo da hierarquia empresarial. Pela própria experiência das fundadoras, elas sabem que se aproximar do discurso feminista não lhes traria vantagens nem na construção de suas próprias carreiras, nem no tipo de ação que desenvolvem a partir de um lugar na estrutura organizacional, isto é: situadas na matriz e ocupando posições intermediárias, distantes das bases. Em seguida, porque, como bem destacou Touraine (2007), a negação do feminismo por parte das mulheres que não foram protagonistas das lutas que eclodiram a partir dos anos 1970 reforça a 
importância desse movimento. Ele abalou de tal forma a estrutura de gênero das sociedades, trazendo muitas conquistas para as mulheres, que suas herdeiras podem se definir de costas para o movimento, não mais se contrapondo aos homens, mas afirmando sua especificidade como mulheres. Essa postura existe no coletivo estudado e pode ser percebida na seguinte fala: "O núcleo anterior tinha algo de 'odiamos o homem' ou 'vamos rasgar o sutiã', tinha algo de extremista, que eu olhava e falava: 'Nossa!' Mas eu não me encaixava legal. Isso está hoje bem mais balanceado."

Apesar desse afastamento com relação ao movimento feminista, elas colocam como objetivo a redução das desigualdades de gênero no universo da empresa. A atuação do Comitê deve garantir que as mulheres não encontrem mais barreiras de gênero na construção de carreiras executivas. "A gente quer na verdade que as mulheres subam, que elas tenham a mesma oportunidade", apontou uma das componentes.

Esse Comitê pode então ser pensado como um coletivo que visa apoiar as mulheres da organização para que possam ter oportunidades iguais aos homens no desenvolvimento profissional. Essa definição levaria a enxergar a construção da sua identidade a partir da ideia de grupo de suporte. Todavia, quando perguntado se elas se identificavam dessa maneira, houve hesitação. "Hoje somos um grupo de suporte, mas talvez não tenhamos essa consciência que vocês acabaram de nos dar. Mas somos sim", ponderou uma delas. "A gente entende que é um trabalho de suporte mesmo para a carreira ou a própria vida pessoal dessa mulher... Eu acho que sim”, destacou outra.

De toda forma, ainda que se reconheçam na identidade de grupo de suporte, cabe questionar o tipo de suporte que é dado ao conjunto das mulheres da organização. Que o trabalho do Comitê apoia o esforço das mulheres que pretendem construir carreira gerencial e que estão mais próximas da matriz, isso se pode afirmar. Mas, e quanto às demais mulheres? A resposta para essa pergunta pode estar nos questionamentos que as próprias componentes desse coletivo se colocam a esse respeito: "Se nós damos suporte a todas as mulheres da organização, é uma incógnita, não é? Porque o nosso Comitê não consegue alcançar todas essas mulheres, e não vejo o Comitê hoje sendo também um local onde as mulheres correm para pedir abrigo."

De fato, percebeu-se que o coletivo, tal como atua hoje, está longe de dar "abrigo" ao conjunto de mulheres da empresa. Perguntada, por exemplo, se o Comitê possui algum tipo de ação voltado para coibir práticas de assédio moral ou sexual, uma componente foi incisiva:

De vez em quando tem alguma coisa assim do tipo: "Estou grávida... e estou sendo destratada pelo meu superior.” Ou então: "Voltei de licença e fui demitida... Isso é um 
absurdo, vocês mulheres deveriam fazer alguma coisa"... Eu já preparei um texto bacana que eu respondo assim: "Nós não somos polícia... cuidamos do trend, não daquele caso... A gente sente muito, manda o seu currículo, vamos ajudar você a arrumar outro emprego, porque não estamos aqui para dedurar o seu chefe para a organização, para dizer que o seu chefe... Não é isso, não nos tornamos um comitê revolucionário..., gasolina na palha, entendeu? Nós nos tornamos um comitê maduro.

Esse relato é complementado pela fala de outra componente, que tratando do mesmo assunto sentenciou: "Então, assim, se a coisa chegou também a esse ponto... é hora de ela pegar a malinha... e tentar... novos... não é? Tem coisas que fogem..., que a gente gostaria muito de ter formas de ajudar, mas infelizmente..." E por que demandas como essas não são ouvidas? Uma interpretação possível remete à própria composição desse coletivo. As componentes do Comitê são, em sua quase totalidade, mulheres brancas, de meia idade, classe média, que trabalham na matriz, ou bem próximas de sua órbita, em posições hierárquicas intermediárias e que pretendem desenvolver carreiras executivas. Consequentemente, elas terminam reproduzindo uma condição específica de ser mulher e se distanciam das demandas de outras mulheres, como se isto fosse um sinal de maturidade. Ademais, evitam assuntos conflituosos e/ou adotam estratégias mais de negociação que de afrontamento diante de conflitos, conforme apontado nas próximas seções.

\section{“QUANDO SOBE O NEGÓCIO LÁ É BRIGA DE CACHORRO LOUCO”: O COMITÊ DE MULHERES NO CONTEXTO DAS POLÍTICAS DE DIVERSIDADE DA EMPRESA}

O Comitê de Mulheres, da mesma forma que os demais grupos de suporte (pessoas com deficiência, negros, GLBTs), responde a um Comitê de Diversidade que, por sua vez, se reporta a um Comitê Executivo. A Figura 1 ilustra o fluxo desse processo.

Figura 1 - Diagrama de funcionamento dos grupos de suporte frente aos Comitês de Diversidade e Executivo

\begin{tabular}{|c|c|c|c|}
\hline $\begin{array}{c}\text { GRUPOS DE } \\
\text { SUPORTE } \\
\text { (Comitês de Mulheres, } \\
\text { Negros, GLBTs, PcDs) }\end{array}$ & propostas
\end{tabular}


Os diferentes Comitês estabelecem um plano de ação anual que é avaliado pelo Comitê de Diversidade. Esse Comitê de Diversidade é composto pela diretora de RH, uma gestora de RH/diversidade e profissionais das áreas negociais, jurídica, de produtos e de marketing. Faz parte dele, também, um representante de cada grupo de suporte. Após a validação dos planos dos Comitês pelo Comitê de Diversidade, caso haja alguma demanda de ordem mais global, encaminha-se a proposta para o Comitê Executivo, o qual inclui o próprio presidente da empresa e seus diretos.

Essa configuração favoreceu o diálogo intragrupos e intergrupos e, na medida em que há uma vinculação com as áreas fins, fortaleceu as ações dos diferentes Comitês e facilitou a transversalidade do tema diversidade na organização. Como estratégia para legitimar os Comitês e dotar-lhes de maior capacidade de influenciar as instâncias superiores de poder, foi definido um "padrinho" para cada um deles, com exceção do Comitê de Mulheres, que abriu mão desse recurso, pois já tinham as suas "conselheiras", as "supermasters". Os "padrinhos" e as "conselheiras" são profissionais que, dadas as posições que ocupam na hierarquia da empresa, estão ligados ao Comitê Executivo, o que facilita o encaminhamento das demandas dos grupos de suporte. As idas e vindas entre os coletivos, o Comitê de Diversidade e o alto escalão, desenvolveu a capacidade de negociar com (e influenciar) as instâncias superiores para defender interesses particulares dos coletivos, como apontou uma gestora de RH.

Quase tudo a gente consegue, porque tem um trabalho muito grande de você fazer análise. Dificilmente, tanto os Comitês, como o Comitê de Diversidade, passam alguma coisa para o Comitê Executivo que não tenha sido estudado profundamente, feito benchmarking em outras empresas..., tem indicadores, tem tudo. Para subir para eles tem que ter todo um estudo.

O preparo anterior às negociações indica, então, uma "profissionalização" da ação coletiva. Propostas inviáveis do ponto de vista financeiro ou jurídico sequer são lançadas. Amparados em informações e levantamentos prévios, os Comitês encaminham propostas que dificilmente são rejeitadas, como também destacou a gestora.

Quando a gente leva uma coisa, já está semi-aprovada. É difícil rejeitarem, porque a gente já sobe com todas as informações. Só para eles falarem: "Cumpra-se”... Por que o resto a gente já viu, já discutiu com o diretor. Pancada isso aí, quando sobe o negócio lá é briga de cachorro louco. 
Se por um lado esse arranjo organizacional, que articula a relação dos diferentes Comitês com o Comitê de Diversidade e o Comitê Executivo, mediada pela existência de "padrinhos" ou “conselheiras", pode ser interpretado como resultado do grau de aprendizagem alcançado por meio da ação coletiva, por outro lado, ele pode também ser visto como um mecanismo de controle utilizado pela direção da empresa. Isso porque se esses mediadores foram instituídos no âmbito da política de diversidade formatada pela direção, então talvez possuam o papel de disciplinar o funcionamento dos grupos. A presença deles afastaria temas polêmicos e conflituosos, que desagradam o corpo diretivo. Isso explicaria a facilidade de aprovação dos projetos em um ambiente metaforicamente denominado "briga de cachorro louco". Todavia, não quer dizer que desapareçam os conflitos e tensões entre os Comitês e executivos situados no alto escalão da empresa. Essas tensões existem, demandando a construção de estratégias elaboradas para lidar com elas, como apresentado a seguir.

\section{“A GENTE VAI À LUTA PARA SE PERPETUAR”: ESTRATÉGiAs E OBSTÁCULOS ÀS AÇÕES DO COMITÊ}

As ações desenvolvidas pelo Comitê de Mulheres para alcançar seus objetivos podem ser resumidas em três conjuntos de iniciativas inter-relacionadas:

- Ações de pesquisa e monitoramento: acompanhamento da demografia organizacional, com análise por área/nível hierárquico; manutenção do equilíbrio entre homens e mulheres no programa de trainee; estudos para reorientar a ação do Comitê.

- Ações voltadas para sensibilização: apresentação de dados e indicadores de gênero da empresa; promoção de eventos; divulgação das ações do Comitê via intranet.

- Ações de mobilização e desenvolvimento: criação de postos de amamentação, orientação para gestantes/maternidade; mentoring para mulheres em posições gerenciais; palestras sobre temas voltados à carreira da gestora; mobilização de executivas situadas em posições de prestígio e poder para atuarem como facilitadoras da ascensão de outras mulheres; estudos para implantação do horário flexível de trabalho.

As temáticas da agenda e as pautas variam em enfoque e revelam nuances da maturidade desse coletivo. Ao mesmo tempo em que são capazes de encaminhar propostas que possam reduzir as desigualdades de gênero, como o programa de mentoring, se dedicam a idealizar e promover eventos 
comemorativos convencionais, tais como: dia das mães, dia das crianças e dia dos pais. Reproduzem assim no universo empresarial o lugar tradicional atribuído à mulher pelo discurso de gênero hegemônico na sociedade: responsável pela sociabilidade familiar, o que inclui a organização das atividades festivas, compra de presentes etc. Em diversas oportunidades esse tipo de discussão dominou a reunião, ocupando quase todo o período do encontro.

As barreiras para a concretização de muitas das ações parecem tênues, embora suficientemente fortes para desvelar questões ainda não superadas. No que se refere à estruturação e atuação do Comitê, aparecem dificuldades tanto na sua dimensão interna (presença flutuante das participantes, pouca continuidade e efetividade das ações), como na dimensão externa, isto é, relativa ao conjunto de mulheres da organização. Quanto a esse ponto, em uma das pesquisas realizadas, perceberam que, ao contrário do que pensavam, nem todas as mulheres querem fazer carreira, o que deveria levá-las a rever o escopo da atuação. De toda forma, julgam que o principal problema que encontram é a natureza voluntária da participação, não prevista no plano de trabalho que cada uma negocia anualmente com seu gestor. Isto faz com que, em determinados momentos, as componentes dediquem tempo insuficiente ao projeto coletivo.

O momento atual representa uma nova fase, que demarca o fim da etapa de sensibilização, como explicita uma integrante: "Já está todo mundo sensibilizado, todo mundo sabe que existe o Comitê. Agora, a gente vai à luta para se perpetuar, para conseguir sustentabilidade.” Essa luta, pelo menos no plano discursivo, não se apresenta como uma estratégia oposicionista. Ao contrário, sempre sugeriram que suas ações são pensadas dentro de um contexto de diversidade e que o esforço é voltado para a transformação das relações de gênero, o que significa estabelecer diálogos não apenas com as mulheres, mas também com os homens. Isto pode indicar uma tentativa de escapar à mentalidade do tipo dual, "nós versus eles”. Falaram da convocação de homens à participação, quer seja em eventos e palestras, quer seja nas pesquisas que coordenaram. Dependendo do grau de envolvimento solicitado, a experiência de retorno não foi sempre positiva. A fala abaixo aponta a reticência dos colegas em participar das reuniões do coletivo.

A empresa tem a preocupação de colocar mulheres e a gente não está tendo a preocupação de colocar homens aqui conosco para pensar junto. A gente já fez convite, tinha uma pessoa de RH que ficou de vir, mas nunca veio. É natural essa resistência, é lógico, porque tem aquele medo de ser tachado. 
A menção dessa integrante ao medo dos homens de serem "tachados" ao participar do Comitê revela que ainda se faz presente nos discursos/relações de gênero dominantes na empresa uma mentalidade dual. Transformar essa realidade é algo que esse coletivo ainda não sabe como fazer.

Eu acredito que o homem que participar as pessoas podem achar que ele não tem nada para fazer, está lá participando do evento das mulheres. É uma coisa meio assim: "Pô, ele não tem o que fazer, então vamos mandar embora."

Os incômodos demonstrados por muitos homens não se restringem, porém, à resistência em participar de atividades do Comitê. Alguns desdenharam da sua existência, sobretudo na origem da experiência. "No início, foi muito difícil, a gente enfrentou muito preconceito porque parecia que nós éramos um Clube de Luluzinhas, que nos reuníamos para trocar receita de bolo, para conversar sobre problemas de marido, de filhos etc. e tal", destacou uma das componentes.

Por conta desses incômodos e preconceitos de muitos homens, perceberam que as estratégias utilizadas para o desenvolvimento das ações nunca deveriam ser de enfrentamento direto. Tangenciar os conflitos era quase um imperativo, como sugere a fala abaixo.

Então, se a gente chegasse lá e falasse assim: "Olha, a gente precisa de $\mathrm{R} \$ 30.000$ porque a gente vai despertar nas mulheres dessa organização a vontade de crescer na carreira", nós não íamos ganhar nada. Mas se a gente chegasse e dissesse assim: "Queremos fazer uma homenagem às mulheres, na semana da mulher. Podemos contar com a sua colaboração?" "Podem." Tanto é assim que um dos maiores admiradores do nosso Comitê hoje é um dos que já soltaram pérolas.

Além de não poderem colocar o conflito abertamente, precisariam utilizar a racionalidade instrumental, que é hegemônica no jogo empresarial. Assumindo uma perspectiva que resvala para um essencialismo na definição das identidades de gênero, uma delas apontou que essa hegemonia da lógica do cálculo se deve ao fato de serem os homens os jogadores dominantes nesse universo.

Eu acho que a melhor estratégia, por conta de que o guia de bordo é masculino, é a estratégia do racional. Acho que esta é a melhor estratégia, sempre, na verdade. No mundo executivo, hein? Pelo amor de Deus! No mundo executivo tem esse estresse: “Aonde estávamos, o que fizemos e aonde estamos hoje?" Então, de longe a melhor estratégia é utilizar os fatos; não dá pra seguir a intuição. 
Mas não são os executivos os únicos a colocarem obstáculos às ações desse coletivo. Segundo elas, algumas executivas também representam barreiras. O raciocínio aqui é o seguinte: as mulheres que ascendem na hierarquia organizacional terminam assumindo comportamentos gerenciais ainda mais rígidos do que aquele apresentado pelos homens, sobretudo quando lideram outras mulheres. Tudo se passa como se elas tivessem se masculinizado para chegar aonde estão. Por conta disso, muitas colaboram, até mais que os homens, para a manutenção das desigualdades de gênero na empresa. Consequentemente, acreditam que essas mulheres são um dos principiais gargalos da ascensão feminina. Contudo, visualizaram a possibilidade de reverter essa ameaça em uma oportunidade. Para tanto, seria necessário deslocar o foco do problema e pensar respostas para a seguinte pergunta: "Como as mulheres de nível hierárquico elevado podem dar suporte a outras e assumir uma postura de facilitadora e multiplicadora?" Colocada essa questão, passavam a enxergar nessa mulher que galgou postos de prestígio e poder uma via para alcançar o principal objetivo do Comitê: apoiar o desenvolvimento da carreira das demais mulheres. "A ideia é que as mulheres parem de competir e comecem a se unir", disse uma delas. Nesse sentido, embora não utilizem esses termos, deram a entender que seria necessário estimular um processo de renegociação das identidades de gênero por parte dessas mulheres, levando-as a assumir um papel ativo pela causa feminina na organização.

\section{AVANÇOS E LIMITES DA AÇÃO DO COMITÊ}

Entre avanços e recuos o Comitê de Mulheres vem construindo sua história. É inegável que sua atuação representa um passo adiante na política de diversidade da empresa. As componentes desse coletivo, ainda que não partam de um ideário feminista e que utilizem estratégias que tangenciam o conflito aberto, têm buscado alterar as relações de gênero na organização, atuando sobre os princípios fundadores da desigualdade. Há indícios de que os padrões de pensar e agir alicerçados nos discursos de gênero hegemônicos na sociedade, e portanto reproduzidos na dinâmica da empresa, estão sendo revistos. Como afirmou a gestora de $\mathrm{RH}$ e representante do Comitê de Diversidade, a despeito das crenças pessoais e preconceitos ainda arraigados nas pessoas, pouco se presenciam falas e situações de constrangimento, como piadas e comentários degradantes em relação às mulheres. Isso porque os profissionais da empresa percebem de maneira cada vez mais nítida que não há espaço para atitudes e comportamentos dessa natureza. Ao contrário, o que se valoriza no perfil do empregado é uma postura 
de convivência com a diversidade. Tal perfil orienta, inclusive, os processos de recrutamento. Assim, a partir da ação do Comitê e da política de diversidade adotada pela empresa, houve transformações nas práticas de admissão. Isto é percebido de forma mais específica no questionamento que o Comitê lançou aos critérios definidos para a seleção de trainees e na influência que exerceu sobre a decisão da direção de mudar a empresa responsável por esse processo, pois seu representante teria dito que o percentual feminino no programa não crescia em razão de as candidatas estarem mais preparadas para discutir novela, do que economia e política. Ademais, uma atenção vem sendo dada ao encarreiramento das mulheres/redução das barreiras a sua promoção. Há um compromisso dos dirigentes com o enfrentamento do teto de vidro, inclusive com o estabelecimento de metas a partir das demandas do Comitê.

Todavia, não é possível concluir este artigo apresentando apenas um quadro otimista. Cabe também pontuar os limites da atuação do Comitê. Inicialmente, é preciso dizer que sua formação não leva em conta a intersecção da localização de gênero com outros panoramas identitários. São basicamente mulheres brancas, de meia idade, classe média e que trabalham em posições hierárquicas intermediárias na matriz que integram o Comitê. Houve no passado recente uma tentativa de aproximação de mulheres com outros perfis. Entretanto, em face das dificuldades encontradas por essas potenciais participantes em contornar as resistências apresentadas por seus gestores em liberá-las para as reuniões e/ou a problemas de outra ordem (o fato de estarem fisicamente distantes da matriz e/ou trabalharem em áreas cuja dinâmica de execução dificulta fortemente o afastamento do local de trabalho), não foi feito um esforço efetivo para criar condições necessárias a essa integração. Portanto, pode-se sugerir que o núcleo representativo desse coletivo não procurou minimizar os desequilíbrios de poder internos ao próprio grupo de identidade.

Ademais, para além da ausência de diversidade no interior do Comitê, não se percebeu uma ação voltada para mapear, em toda a sua complexidade, as demandas do conjunto de mulheres de uma organização que está presente em quase todo o território nacional. De certa forma, pode-se dizer que o núcleo é mais sensível às demandas da direção da empresa, do que às vozes daquelas que representam suas bases e deveriam lhe conferir legitimidade. Nesse sentido, seria mais um grupo de suporte à política de diversidade implantada pela direção, do que ao conjunto de mulheres da organização.

Vale ressaltar também que a autonomia conferida pela direção da empresa ao funcionamento do Comitê, como não poderia deixar de ser, é relativa. Por um lado, elas possuem o apoio pessoal do presidente, mas, por outro, o arranjo organizacional no qual está inscrito esse coletivo, ainda que acolha muitas das suas reivindicações e/ou propostas, garante seu controle e disciplina sua atuação. 
Se o Comitê e a direção da empresa vão avançar no sentido de responder às discussões apontadas nesta pesquisa é algo que só o tempo dirá. De toda forma, a seguinte fala da sua atual líder revela uma postura reflexiva em face desses desafios:

"A necessidade que nós temos de influenciar e espalhar nossas ações pelo Brasil é muito maior do que hoje a gente consegue. A nossa influência é mínima. É um coletivo também com pouco tempo de vida. Eu acho que a gente faz $5 \%$ do que poderia fazer.”

Talvez por isso ela expresse de forma tão nítida a crise que, conforme sinalizado neste artigo, marca hoje a identidade do Comitê: "Eu acho que é um coletivo mobilizado em fazer a diferença, fazer a mudança, e talvez ainda sem ter encontrado o rumo certo, não é?"

\section{CONSIDERAÇÕES FINAIS}

O que se pode concluir sobre grupos de suporte, ação coletiva e gênero no contexto das políticas de gestão da diversidade a partir da análise do Comitê de Mulheres da empresa objeto dessa pesquisa? Abordou-se nesse artigo uma experiência de afirmação de um grupo social em situação de desvantagem em relação a outros, a fim de provocar mudanças. Trata-se, portanto, de uma ação coletiva no sentido de Tajfel e Turner (1979). Contudo, o núcleo representativo desse grupo, embora comprometido com a promoção de melhorias para todo o segmento que representa (WRIGHT e TROOP, 2002), possui pouca abertura para a escuta das demandas do conjunto de mulheres da organização. Situado na matriz da corporação no Brasil, na cidade de São Paulo, não criou mecanismos de interação com profissionais posicionadas nos mais distantes estados da federação. Ademais, embora esse Comitê represente uma superação da tendência à inércia e um esforço de articulação de atores estruturalmente em desvantagem, a fim de reduzir as iniquidades de poder (SIMPSON e MACY, 2004), presta pouco apoio emocional às suas representadas para que possam encarar situações opressivas. Nesse sentido, não apresenta as nuances de um grupo de suporte tal como pensados por Yalom (1995) e Vandenbos (2007).

A experiência analisada aproxima-se mais do modelo de grupo de suporte destacado por Riordan e Kahnweiler (1996), cujo propósito é aprender como alcançar metas de carreira. Os resultados desse tipo de coletivo, segundo esses autores, podem ser, entre outros, o incremento de habilidades 
estratégicas, a ampliação da rede de contatos e o desenvolvimento da capacidade de liderança. Estes são justamente os principais objetivos que o Comitê de Mulheres da empresa pesquisada persegue.

Cabe destacar, com Hargrave e Van de Ven (2006), que o caso estudado representa, sem dúvida, uma inovação no âmbito das políticas de gestão da diversidade, fruto de uma abertura para o exercício de uma ação coletiva. Nesse sentido, vale lembrar que estudos clássicos que tratam das questões de gênero no universo empresarial apontaram o caráter subalterno da condição das mulheres nas empresas (SEGNINI, 1998) e/ou as estratégias individuais que elas utilizam para conquistar espaço e desenvolver a carreira (BELLE, 1993). A experiência estudada aqui avança em relação a essas estratégias individualizadas. Isto porque, dentro do arranjo organizacional da política de diversidade da empresa, existe uma abertura para a articulação e fortalecimento de um grupo de identidade, o Comitê de Mulheres, bem como um espaço para onde demandas organizadas de maneira coletiva podem fluir, o Comitê de Diversidade e o Comitê Executivo.

Isto não significa, entretanto, que a existência desse novo arranjo garanta, por si só, uma transformação profunda das desigualdades de gênero na organização. A partir do caso aqui analisado, afirma-se isso por duas razões: a) o grupo de suporte pode não refletir, em toda a sua complexidade, as demandas do conjunto de seus representados; b) o trânsito das suas demandas para o Comitê de Diversidade e o Comitê Executivo talvez não permita que os dissensos sejam debatidos abertamente. Em outras palavras, as demandas coletivas, embora sejam ouvidas, podem não encontrar espaço para serem formuladas na linguagem do conflito, tal como na arena política mais ampla de disputas por direitos na sociedade.

Retomando a problematização lançada na introdução deste artigo, cabe apontar a presença de um paradoxo nas políticas de diversidade da empresa estudada, que corrobora a preocupação apontada no parágrafo anterior. Os resultados do trabalho de campo permitem inferir que o Comitê de Mulheres configura-se como um processo de emancipação, sinalizando para práticas gerenciais mais inclusivas, igualitárias e participativas. Isto está de acordo com um dos fundamentos da política emancipatória, tal qual entendida por Giddens (2002), no que se refere à capacidade expressa pelo Comitê de buscar reduzir a desigualdade e a opressão, tentar rever a distribuição dos recursos e do poder, lutando assim pelos imperativos da ética e da justiça. Ou seja, o coletivo procura conquistar maior igualdade e participação e romper com a dominação hierárquica exercida pelos homens, ainda que por vezes reproduza a rigidez do costume, ao reforçar no espaço da empresa papéis de gênero tradicionais (caso dos eventos comemorativos do dia das mães, dia das crianças e dia dos pais) e não incorpore, em toda a sua complexidade, as demandas do conjunto de mulheres da organização. Mas, o arranjo 
organizacional no qual está inserido esse Comitê representa, também, um mecanismo de controle, que visa disciplinar o seu funcionamento. Nesse caso, o coletivo não consegue minimizar o excesso de ações regulatórias (SANTOS, 2000b) que limitam sua autonomia e, consequentemente, seu grau de emancipação.

De toda forma, acredita-se que as iniciativas individuais não garantirão o avanço desse processo de emancipação. Individualmente, os sujeitos historicamente discriminados e excluídos das posições de maior poder, prestígio e remuneração nas organizações estão muito mais vulneráveis ao controle por parte dos grupos majoritários. Sendo assim, são sobretudo as ações coletivas que permitem vislumbrar possibilidades mais consistentes de transformação da condição de subalternidade. A questão que se coloca então é a de saber até que ponto esses grupos formados por indivíduos em situação de desvantagem no âmbito das empresas podem, no processo de emancipação, encontrar e/ou ajudar a construir arranjos organizacionais mais permeáveis a sua participação plena e a expressão de suas demandas de maneira mais complexa. Quanto a esse ponto, em função do caráter ainda recente, tanto internacionalmente quanto no Brasil, das experiências de formação de grupos de suporte nas empresas, ainda é cedo para dar um vaticínio. Faz-se, sim, necessário avançar as pesquisas em gestão da diversidade, grupos de suporte e ação coletiva, seja no âmbito das relações de gênero, seja no que se refere a outros marcadores sociais da diferença.

\section{NOTA DOS AUTORES}

O professor Pedro Jamie é Doutorando pela Université Lumière Lyon II, como bolsista CAPES no quadro do Colégio Doutoral Franco-Brasileiro.

\section{REFERÊNCIAS}

AKTOUF, O. Méthodologie des sciences sociales et approche qualitative des organizations. Québec: Presses de L’Université du Québec, 1987.

ALDERFER, C. P; SMITH, K. K. Studying intergroup relations embedded in organizations. Administrative Science Quarterly, v. 27, n. 1, 1982. 
ALVES, M. A; GALEÃO-SILVA, L. G. A crítica da gestão da diversidade nas organizações. RAErevista de administração de empresas, v. 44, n. 3, p. 20-29, 2004.

ANDRÉ, M. E. D. A. Etnografia da prática escolar. Campinas: Papirus, 1995.

BATEMAN, T. S; SNELL, S. A. Administração: construindo vantagem competitiva. São Paulo: Atlas, 1998.

BECKER, H. Observação social e estudos de caso sociais. In: Métodos de pesquisa em ciências sociais. São Paulo: Hucitec, 1999.

BERTAUX, D. Le récit de vie. Paris: Armand Colin, 2005.

BELLE, F. Executivas: quais diferenças na diferença? In: CHANLAT, J. F. O indivíduo na organização: dimensões esquecidas. São Paulo: Atlas, 1993. v. 2.

BOURDIEU, P. A dominação masculina. Rio de Janeiro: Bertrand Brasil, 2005.

BUTTLER, J. Problemas de gênero: feminismo e subversão da identidade. Rio de Janeiro: Civilização Brasileira, 2003.

CARDOSO de OLIVEIRA, R. C. O trabalho do antropólogo. São Paulo: Editora UNESP, 2000.

CHARMES, J; WIERINGA, S. Measuring women's empowerment: an assessment of the genderrelated development index and the gender empowerment measure. Journal of Human Development, v. 4, n. 3, Nov. 2003.

CLIFFORD, J. A experiência etnográfica: antropologia e literatura no século XX. Rio de Janeiro: Editora UFRJ, 1998.

CORRÊA, M. O sexo da dominação. Novos Estudos, v. 54, 1999. 
COX JR., T; BLAKE, S. Managing cultural diversity: implication for organizational competitiveness. The Academy of Management Executive, v. 5, n. 3, 1991.

CZARNIAWSKA, B. A narrative approach to organization studies. London: Sage, 1998.

CZARNIAWSKA, B. Narrative, interviews and organizations. In: GUBRIUM, J.; HOLSTEIN, J. Handbook of interview research. London: Sage, 2002.

DEAUX, K. e outros. Ideologies of diversity and inequality: predicting collective action in group varying in ethnicity and immigrant status. Political Psychology, v. 27, n. 1, 2006.

ELY, R; MEYERSON, D. Moving from gender to diversity in organizational diagnosis and intervention. The diversity factor, v. 7, n. 3, 1999.

FLEURY, M. T. L. Gerenciando a diversidade cultural: experiências de empresas brasileiras. $R A E-$ revista de administração de empresas, v. 40, n. 3, p. 18-25, 2000.

FOURNIER, M. À propos de la domination masculine. Sciences humaines, numéro special l'oeuvre de Pierre Bourdieu, 2002.

GEERTZ, C. A interpretação das culturas. Rio de Janeiro: Guanabara Koogan, 1989.

GEERTZ, C. O saber local: novos ensaios de antropologia interpretativa. Petrópolis: Vozes, 1998.

GIANNASI, I. Mulheres em pé de igualdade: executivas formam grupo para discutir participação no mercado e ampliar rede de contatos. O Estado de São Paulo. São Paulo, Caderno Oportunidades, 9 jul. 2006.

GIDDENS, A. Modernidade e identidade. Rio de Janeiro: Zahar, 2002.

GODOY, A. S. Pesquisa qualitativa: tipos fundamentais. Revista de Administração de Empresas, v. 35, n. 3, 1995. 
GODOY, A. S. Estudo de caso qualitativo. In: SILVA, A. B; GODOI, C. K; BANDEIRA-DE-

MELLO, R. Pesquisa qualitativa em estudos organizacionais: paradigmas, estratégias e métodos. São Paulo: Saraiva, 2006.

HAMEL, J. e outros. Case study methods. London: Sage, 1993.

HANASHIRO, D. M. M. Convivendo com a diversidade cultural. In: HANASHIRO, D. M. M; TEIXEIRA, M. L. M; ZACCARELLI, L. M. (Org). Gestão do fator humano: uma visão baseada em stakeholders. São Paulo: Saraiva, 2007.

HANNERZ, U. Fluxos, fronteiras, híbridos: palavras-chave da antropologia transnacional. Mana Estudos de Antropologia Social, v. 3, n. 1, 1997.

HARGRAVE, T, J; VAN DE VEN, A. H. A collective action model of institutional innovation. Academy of Management Review, v. 31, n. 4, 2006.

JAIME, P. Pesquisa em organizações: por uma abordagem etnográfica. Civitas, v. 3, n. 2, 2003.

KAHNWEILER, M. W; RIORDAN, J. R. Job and employee support groups: past and prologue. The Career Development Quarterly, v. 47, 1998.

KAUFMANN, J. C. L'entretien compréhensif. Paris: Armand Colin, 2007.

LAPLANTINE, F. La description ethnographique. Paris: Nathan, 2000.

L’ESTOILE, B. L'invention du terrain. Sciences Humaines, hors-série n. 23. Paris: Éditions Sciences Humaines, 1999.

MALINOWSKI, B. Argonautas do pacífico ocidental. São Paulo: Abril Cultural, 1984. 
ARTIGOS - DA ESTRATÉGIA INDIVIDUAL À AÇÃO COLETIVA: GRUPOS DE SUPORTE E GÊNERO NO CONTEXTO DA GESTÃO DA DIVERSIDADE

Janette Brunstein - Pedro Jaime

MOORE, H. Understanding sex and gender. In: INGOLD, T. Companion encyclopedia of anthropology. London: Routledge, 1994.

MOORE, H. Fantasias de poder e fantasias de identidade: gênero, raça e violência. Cadernos Pagu, n. $14,2000$.

NKOMO, S. M; COX JR, T. Diversidade e identidade nas organizações. In: CLEGG, S. R. e outros. Handbook de estudos organizacionais. São Paulo: Atlas, 1998.

O ESTADO DE SÃO PAULO. Executivas se unem para ampliar território. São Paulo, 7 abr. 2003. Disponível em http://www.estadao.com.br. Acesso em 20.04.2006.

OLIVIER de SARDAN, J. P. La rigueur du qualitatif: les contraintes empiriques de l'interprétation sócio-anthropologique. Louvain: Academia Bruylant, 2008.

OSÓRIO, C. Poder político e protagonismo feminino em Moçambique. In: SANTOS, B. S. (Org). Democratizando a democracia: os caminhos da democracia participativa.. Rio de Janeiro: Civilização Brasileira, 2002.

RABINOW, P. Reflexiones sobre un trabajo de campo en Marruecos. Madrid: Júcar, 1992.

RIORDAN, J. R; KAHNWEILER, M. W. Job support groups: three configurations. Journal of counseling and development, v. 74, 1996.

ROSALDO, M; LAMPHERE, L. A mulher, a cultura e a sociedade. Rio de Janeiro: Paz e Terra, 1979. SANTOS, B. S. Pela mão de Alice: o social e o político na pós-modernidade. São Paulo: Cortez, 2000a.

SANTOS, B. S. A crítica da razão indolente: contra o desperdício da experiência. São Paulo: Cortez, $2000 \mathrm{~b}$. 
ARTIGOS - DA ESTRATÉGIA INDIVIDUAL À AÇÃO COLETIVA: GRUPOS DE SUPORTE E GÊNERO NO CONTEXTO DA GESTÃO DA DIVERSIDADE

Janette Brunstein - Pedro Jaime

SCHWATTZMAN, H. Ethnography in organizations. London: Sage, 1992.

SCOTT, J. Gender and politics of history. New York: Columbia University Press, 1988.

SEGNINI, L. Mulheres no trabalho bancário: difusão tecnológica, qualificação e relações de gênero. São Paulo: Edusp, 1998.

SERVA, M; JAIME, P. Observação participante e pesquisa em administração: uma postura antropológica. RAE-revista de administração de empresas, v. 35, n. 1, p. 64-79, 1995.

SIMPSON, B; MACY, M. Power, identity, and collective action in social exchange. Social Forces, v. 82, n. 4, 2004.

TAJFEL, H; TURNER, J. An integrative theory of intergroup conflict. In: AUSTIN, W. G; WORCHEL, S. (Eds). The social psychology of intergroup relations. Monterey: Brooks-Cole, 1979.

TOURAINE, A. Igualdade e diversidade. São Paulo: Edusc, 1998.

TOURAINE, A. O mundo das mulheres. Petrópolis: Vozes, 2007.

VANDENBOS, G. R. APA dictionary of psychology. Washington DC: American Psychological Association, 2007.

WRIGHT, S. C; TROOP, L. R. Collective action in response to disadvantage: intergroup perceptions, social identification, and social change. In: WALKER, I.; SMITH, H. J. (Eds). Relative deprivation: specification, development, and integration. Cambridge: Cambridge University Press, 2002.

YALOM, I. D. The theory and practice of group psychotherapy. New York: Basic Books, 1995.

YIN, R. K. Estudo de caso: planejamento e método. Porto Alegre, Bookman, 2001. 